\title{
Clinical and Histopathological Features of Genitourinary Sarcomas: Our Experiences and Case Series at a Single Center
}

\author{
(1) İsmail Selvi MD¹, • Eşref Oğuz Güven $\mathrm{MD}^{2}$ \\ ${ }^{1}$ Karabük University Training and Research Hospital, Clinic of Urology, Karabük, Turkey \\ 2 University of Health Sciences Ankara Dr. Abdurrahman Yurtaslan Oncology Training and Research Hospital, Clinic of Urology, Ankara, Turkey
}

\begin{abstract}
Objective: The incidence of genitourinary sarcomas is very low, so the published reports in the literature are very limited. We aimed to present our experiences of eight cases originating from various genitourinary organs treated in our clinic.

Materials and Methods: We retrospectively reviewed the data and postoperative follow-up findings of eight cases aged 3-72 years who were diagnosed as genitourinary sarcoma and treated between January 2013 and February 2017.

Results: All eight cases were male and the mean age at diagnosis was 47.87 (range $=3-72$ ) years. The most common site was paratesticular area (five cases, 62.5\%) followed by kidney (two cases, 25\%) and prostate (one case, 12.5\%). Histological types of tumors were rhabdomyosarcoma (RMS) (two cases, 25\%), liposarcoma (LPS) (two cases, 25\%), leiomyosarcoma (LMS) (two cases, 25\%), synovial sarcoma (one case, 12.5\%) and malignant fibrous histiostoma (MFH) (one case, 12.5\%). At a median follow-up of 23.5 (range $=4-62$ ) months, the recurrence-free and progression-free survival rate was $50 \%$, while the overall survival rate was $50 \%$. Among the five paratesticular sarcomas, the worst prognosis was seen in LMS (local recurrence at the $4^{\text {th }}$, overall survival was 28 months) and MFH (local recurrence at the $8^{\text {th }}$, overall survival was 33 months). Among all sarcoma cases, LMS and synovial sarcoma were the histologic types with the worst prognosis. The histological types with the best prognosis were LPS and RMS with no recurrence or progression during follow-up. In all cases with a median tumor size of $52.5 \mathrm{~mm}$ (range =11-210), LPS was found to have a better prognosis, although the largest tumor size was in renal LPS. According to FNCLCC classifications, local recurrence-free survival was significantly higher in grade II sarcomas than in grade III $(p=0.042)$.

Conclusion: Histopathological features and oncologic outcomes of genitourinary sarcomas differ. The prognosis of paratesticular sarcomas is better than other genitourinary organ sarcomas. LPS has higher cure rates after treatment in histological subtypes. The prognosis of histopathologically poorly differentiated subtypes and high-grade tumors is poor. If adjuvant treatments are not added, they may be fatal with local recurrence or distant metastasis in a short time.
\end{abstract}

Keywords: FNCLCC grading system, overall survival, genitourinary sarcomas, paratesticular sarcomas

\section{Introduction}

Genitourinary sarcomas (GUS) originate from embryonic mesenchymal cells and are very rare tumors with poor prognosis. Sarcomas constitute approximately $1 \%$ of all malignancies (1). While less than $5 \%$ of all sarcomas originate from the genitourinary system, GUS accounts for $1-2 \%$ of all malignant genitourinary tumors (1). In the literature, studies with a large patient population are very few due to the rarity of GUS $(2,3)$.
Therefore, there is not much information about its natural course and prognosis. To our knowledge, the two largest series of patients belong to Sichuan University West China Hospital (188 patients) and Memorial Sloan-Kettering Cancer Center (131 patients) $(3,4)$.

Tumor stage, grade, size and localization are important in predicting resectability and survival $(2,3)$. While complete surgical resection is known to increase survival rates, adjuvant treatment protocols have not yet been standardized and their

This article was accepted to Interdisciplinary Urooncology Meeting in Ankara on December 14-16 2018 as an oral presentation (Presentation number: SS026). Due to reasons beyond our control, owing to we could not be able to attend the day the presentation would be presented, the statement was removed from the abstract book. Because of this, we owe meeting edit committee and scientific secretary an apology.

Address for Correspondence: İsmail Selvi MD, Karabük University Training and Research Hospital, Clinic of Urology, Karabük, Turkey

E-mail: ismselvi33@hotmail.com ORCID: orcid.org/0000-0003-3578-0732 Received: 01.01.2019 Accepted: 09.01.2019 
contribution to survival varies in different studies (3). Since our knowledge about GUS is limited, in this study, we aimed to evaluate the prognostic factors that may have an impact on oncologic outcomes by examining the clinicopathological features of GUS patients diagnosed in our clinic.

\section{Materials and Methods}

We retrospectively reviewed the clinical and pathological data and the postoperative follow-up findings of eight cases aged 3-72 years who were diagnosed as genitourinary tract soft tissue sarcoma between January 2013 and February 2017 in our clinic. Demographic data of the patients, presenting complaint, primary organ, tumor side, localization, metastasis at the time of diagnosis, pathological tissue diagnosis, pathological tumor size, applied surgical treatments, surgical resection status (complete/ incomplete), surgical margin positivity, adjuvant therapies during postoperative follow-up, postoperative follow-up period, local recurrence, progression and survival were recorded.

In the pathological examination of GUS, all cases were graded according to the classification determined by "FNCLCC" (The French Fédération Nationale des Centers de Lutte Contre le Cancer) and the pathological grade of each patient was recorded. In this system, three parameters as tumor differentiation, mitotic activity and tumor necrosis degree, are scored separately and according to the total score, patients are classified as grade I, II, III (low, medium, high grade) in terms of sarcoma grade $(5,6)$.

\section{Statistical Analysis}

Kaplan-Meier method was used for survival analysis and differences between patient groups were evaluated by log rank test. This study was not suitable for the multivariate model because of the small sample size. Analyses were performed using IBM SPSS Statistics 21 (IBM, Armonk, NY USA) software. $\mathrm{p}<0.05$ was considered statistically significant.

\section{Results}

All eight patients included in the study were male and the mean age at diagnosis was 47.87 (range $=3-72$ ) years. The most common site was paratesticular area (five cases, $62.5 \%$ ) followed by kidney (two cases, 25\%) and prostate (one case, $12.5 \%)$. The most common presenting complaint was palpable mass, which was present in all five paratesticular sarcomas (four in the scrotum and one in the inguinal region). Histological types of tumors were rhabdomyosarcoma (RMS) (two cases, 25\%), liposarcoma (LPS) (two cases, 25\%), leiomyosarcoma (LMS) (two cases, 25\%), synovial sarcoma (SS) (one case, $12.5 \%$ ) and malignant fibrous histiostoma (MFH) (one case, $12.5 \%)$. Seven patients (87.5\%) underwent surgical excision, while one of these patients (14.2\%) had positive surgical margins.

During the median follow-up of 23.5 (range = 4-62) months, none of the eight patients received neoadjuvant therapy. Adjuvant chemotherapy (CT) was planned in five patients, adjuvant radiotherapy (RT) in one patient, palliative RT + CT in one patient and one patient was followed-up. Local recurrence developed in two patients (25\%) after a mean of 6 months (range $=4-8$ months). In two cases, progression was observed in a very short period of 4 months (range $=3-5$ months) after the diagnosis and cancer-related death occurred at $5^{\text {th }}$ month. The only metastatic patient at the time of diagnosis was prostate LMS, and metastasis was observed in paraaortic area, paravertebral area, lung, spleen and liver.

Among the five paratesticular sarcomas, the worst prognosis was seen in LMS, which had local recurrence in the early postoperative period the $4^{\text {th }}$ month, although radical orchiectomy followed by adjuvant RT was performed due to surgical margin positivity. After being out of follow-up, it was learned that the overall survival of this patient was 28 months. In another case of MFH with a poor prognosis, local recurrence was observed the $8^{\text {th }}$ month and the patient was out of followup. In this patient, the overall survival was 33 months.

Among the eight GUS, the histological types with the worst prognosis were LMS and SS. One of our two LMS cases had prostate origin and surgical resection could not be performed in this patient who was metastatic at the time of diagnosis due to poor general condition. Despite palliative RT + CT treatment, the patient died at the $5^{\text {th }}$ month. The other patient with LMS had paratesticular origin. The case of SS had of renal origin and progressed rapidly within two months and died at the $5^{\text {th }}$ month despite debulking surgery + adjuvant CT.

The histologic types with the best prognosis were LPS (one paratesticular and one renal origin) and RMS (two paratesticular origin) with no recurrence or progression during follow-up. The median tumor size was $52.5 \mathrm{~mm}$ (range $=11-210$ ) in all eight cases. Although the largest tumor size belongs to renal LPS, we observed that LPS has a better prognosis among histological subtypes. Table 1 presents the characteristics of the cases.

During a median follow-up of 23.5 (range = 4-62) months, the recurrence-free and progression-free survival rate was $50 \%$ and the overall survival rate was $50 \%$. Oncologic results were evaluated in terms of tumor histopathologic subtype, FNCLCC grading system, primary organ from which the tumor developed and tumor size $>5 \mathrm{~cm}$. According to FNCLCC classification, local recurrence-free survival was significantly higher in grade II sarcomas than in grade III ( $p=0.042$, Figure 1) in Kaplan-Meier analysis. Other parameters did not significantly affect local recurrence-free survival, metastasis-free survival and cancer-specific survival (Figures 2,3,4).

\section{Discussion}

Since the series reported in the literature on GUS include a relatively small number of patients, there is still limited consensus on optimal treatment regimens and follow-up protocols $(7,8)$. In the relatively large number of patients reported in the literature, LPS was the most common type of all soft tissue sarcomas. LMS (29\%) was the most common histological type among all GUS, followed by LPS (26\%) and RMS (18\%) $(3,9)$. In the most recent and large-scale study by Wang et al. (4), the incidence was $41 \%$ for LMS, $20.2 \%$ for LPS and $19.1 \%$ for RMS. In our small case series study, we found equal numbers (two cases, 25\%) of all three types. In the literature, survival rates in bladder and paratesticular sarcomas have been reported to be higher than in sarcomas originating from prostate and 
Selvi and Güven

Our Series of Genitourinary Sarcomas

\begin{tabular}{|c|c|c|c|c|c|c|c|c|c|}
\hline 1 & 19 & Male & $\begin{array}{l}\text { Right scrotal } \\
\text { swelling }\end{array}$ & Paratesticular & $\begin{array}{l}\text { Spindle } \\
\text { cell variant } \\
\text { RMS } \\
\text { Grade } 2\end{array}$ & $55 \times 45 \times 45$ & $\begin{array}{l}\text { Right inguinal orchiectomy + } \\
7 \text { cycles of CT due to left } \\
\text { paraaortic } \\
10 \times 8 \text { mm diameter lymph } \\
\text { node (vincristine, actinomycin } \\
\text { D, cyclophosphamide) }\end{array}$ & 62 & $\begin{array}{l}\text { No relapse, } \\
\text { Survivor }\end{array}$ \\
\hline 2 & 59 & Male & $\begin{array}{l}\text { Right scrotal } \\
\text { swelling }\end{array}$ & Paratesticular & $\begin{array}{l}\text { LPS } \\
\text { Grade } 2\end{array}$ & $45 \times 40 \times 27$ & $\begin{array}{l}\text { Right inguinal orchiectomy + } \\
\text { active surveillance }\end{array}$ & 48 & $\begin{array}{l}\text { No relapse, } \\
\text { Survivor }\end{array}$ \\
\hline 3 & 72 & Male & $\begin{array}{l}\text { Swelling } \\
\text { in the } \\
\text { left inguinal } \\
\text { region }\end{array}$ & Paratesticular & $\begin{array}{l}\text { LMS } \\
\text { Grade } 3\end{array}$ & $50 \times 40 \times 30$ & $\begin{array}{l}\text { Left inguinal orchiectomy } \\
+ \text { inguinal mass excision + } \\
\text { adjuvant RT due to surgical } \\
\text { margin positivity }\end{array}$ & 4 & $\begin{array}{l}\text { Local recurrence at the } 4^{\text {th }} \\
\text { month } \\
\text { The patient was out of } \\
\text { followed up. } \\
\text { It was learned that he } \\
\text { dead at the } 28^{\text {th }} \text { month. }\end{array}$ \\
\hline 4 & 3 & Male & $\begin{array}{l}\text { Right } \\
\text { scrotal } \\
\text { swelling }\end{array}$ & Paratesticular & $\begin{array}{l}\text { Embryonal } \\
\text { RMS Grade } 2\end{array}$ & $11 \times 10 \times 5$ & $\begin{array}{l}\text { Right inguinal orchiectomy + } \\
12 \text { cycles of CT (vincristine) }\end{array}$ & 39 & $\begin{array}{l}\text { No relapse, } \\
\text { Survivor }\end{array}$ \\
\hline 5 & 60 & Male & $\begin{array}{l}\text { Left scrotal } \\
\text { swelling }\end{array}$ & Paratesticular & $\begin{array}{l}\text { Malignant } \\
\text { fibrous } \\
\text { histiocytoma } \\
\text { Grade } 3\end{array}$ & $50 \times 49 \times 45$ & $\begin{array}{l}\text { Left inguinal orchiectomy + } \\
4 \text { cycles of CT (ifosfamide, } \\
\text { mesna, a } \\
\text { driamycin) }\end{array}$ & 8 & $\begin{array}{l}\text { Local recurrence at the } 8^{\text {th }} \\
\text { month } \\
\text { The patient was out of } \\
\text { followed up. } \\
\text { It was learned that he } \\
\text { dead at the } 33^{\text {th }} \text { month. }\end{array}$ \\
\hline 6 & 47 & Male & $\begin{array}{l}\text { Left flank } \\
\text { and } \\
\text { abdominal } \\
\text { pain }\end{array}$ & Renal & $\begin{array}{l}\text { Synovial } \\
\text { sarcoma } \\
\text { Grade } 3\end{array}$ & $90 \times 70 \times 60$ & $\begin{array}{l}\text { Left radical nephrectomy, } \\
\text { Splenectomy + retroperitoneal } \\
\text { metastasectomy } \\
\text { for metastasis } 2 \text { months later } \\
+ \text { single dose CT (doxorubicin) }\end{array}$ & 5 & $\begin{array}{l}\text { Multiple metastases in the } \\
\text { lung, spleen, paraaortic and } \\
\text { paravertebral areas at the } \\
2^{\text {th }} \text { month. } \\
\text { Metastasis in the liver at the } \\
4^{\text {th }} \text { month. } \\
\text { Dead at the } 5^{\text {th }} \text { month }\end{array}$ \\
\hline 7 & 57 & Male & $\begin{array}{l}\text { Bilateral } \\
\text { lower } \\
\text { extremity } \\
\text { edema }\end{array}$ & $\begin{array}{l}\text { Renal, } \\
\text { Mass that } \\
\text { makes } \\
\text { pressure to } \\
\text { vena cava }\end{array}$ & $\begin{array}{l}\text { LPS } \\
\text { Grade } 2\end{array}$ & $210 \times 200 \times 90$ & $\begin{array}{l}\text { Right radical nephrectomy + } \\
\text { right adrenalectomy + } \\
4 \text { cycles of adjuvant CT } \\
\text { (ifosfamide, mesna, } \\
\text { adriamycin) }\end{array}$ & 44 & $\begin{array}{l}\text { No relapse, } \\
\text { Survivor }\end{array}$ \\
\hline 8 & 66 & Male & $\begin{array}{l}\text { Weakness, } \\
\text { constipation, } \\
\text { perineal pain }\end{array}$ & Prostate & $\begin{array}{l}\text { LMS } \\
\text { Grade } 3 \\
\text { (Outcome of } \\
\text { TRUS-prostate } \\
\text { biopsy) }\end{array}$ & $55 \times 35 \times 30$ & $\begin{array}{l}\text { At the time of diagnosis, } \\
\text { PSA=12, } \\
\text { invasion of anal canal } \\
\text { and pelvic } \\
\text { floor muscles, metastasis } \\
\text { in lung } \\
\text { Palliative RT to the } \\
\text { prostatic area + } \\
2 \text { cycles of CT } \\
\text { (doxorubicin, } \\
\text { cyclophosphamide, } \\
\text { cisplatin) }\end{array}$ & 5 & $\begin{array}{l}\text { PSA progression } \\
\text { at the } 3^{\text {th }} \text { month } \\
\text { Dead at the } 5^{\text {th }} \\
\text { month }\end{array}$ \\
\hline
\end{tabular}

kidney $(3,4)$. This condition was attributed to the diagnosis in early stages due to scrotal swelling in paratesticular sarcoma and early presentation of patients with hematuria in bladder sarcoma (2). Similarly, recurrence-free and progression-free survival rates were higher in paratesticular cases than in renal and prostate cases (60\% vs $33.3 \%$ ) in our study.

Retroperitoneal soft tissue sarcomas constitute $10-20 \%$ of all sarcomas. Eighty percent of patients present with intraabdominal mass symptoms, and the second most common symptom is pain. Since these masses do not show any symptoms until they reach a large size, they are diagnosed in the late period (10). The most common histological type is LPS, which also has better biological course and prognosis
(11). However, tumor prognosis may vary depending on tumor grade, size and stage (12). In our study, a patient with renal LPS presented to the advanced clinical stage with bilateral lower extremity edema because of a mass compressing the vena cava at the time of diagnosis. The mass was resected completely by radical nephrectomy + adrenalectomy and histopathological grade was grade II according to FNCLCC. Following four cycles of adjuvant $\mathrm{CT}$, no recurrence or progression was observed in the 44-month follow-up.

Prostate sarcomas are extremely rare and data about treatment modalities and survival rates is based on case reports and expert opinions. Surgical resection is the mainstay of treatment in these cases, usually by cystoprostatectomy or total pelvic 


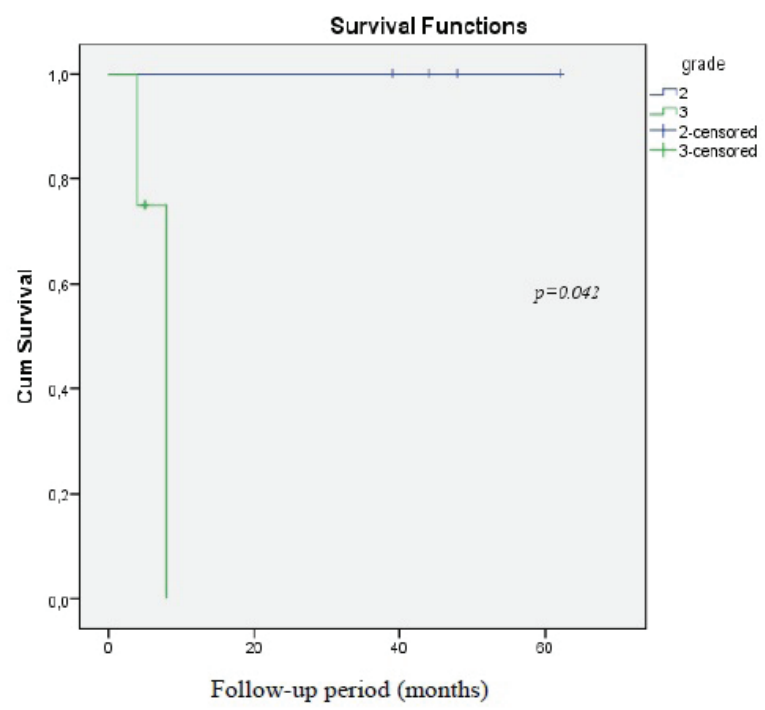

Figure 1. Kaplan-Meier survival curves of all cases according to histopathologic grade

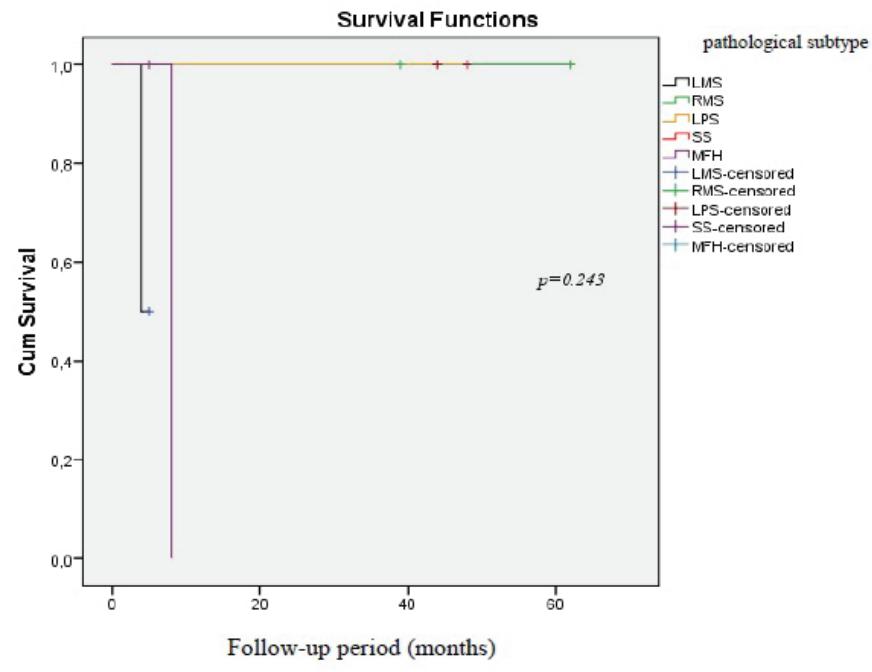

Figure 2. Kaplan-Meier survival curves of all cases according to pathological subtype

LMS: Leiomyosarcoma, RMS: Rhabdomyosarcoma, LPS: Liposarcoma, SS: Synovial sarcoma

exenteration. In a series of 21 patients, 1, 3 and 5-year survival rates were reported as $81 \%, 43 \%$ and $38 \%$, respectively (13). LMS is the most common primary sarcoma of the prostate in adults and constitutes $38-52 \%$ of primary prostate sarcomas. It has a highly aggressive clinical course (14). Due to its rarity, definitive treatment protocols have not been established yet. Numerous publications have reported widespread metastasis to the lung and liver in approximately one-third of patients at the time of diagnosis or shortly after diagnosis. In addition to surgical resection, multimodal treatment combinations such as neoadjuvant or adjuvant CT and RT are recommended $(8,14)$. In our case, FNCLCC grade III LMS was diagnosed in the biopsy performed due to high PSA level, and invasion of the anal canal and pelvic floor muscles and lung metastasis were present at

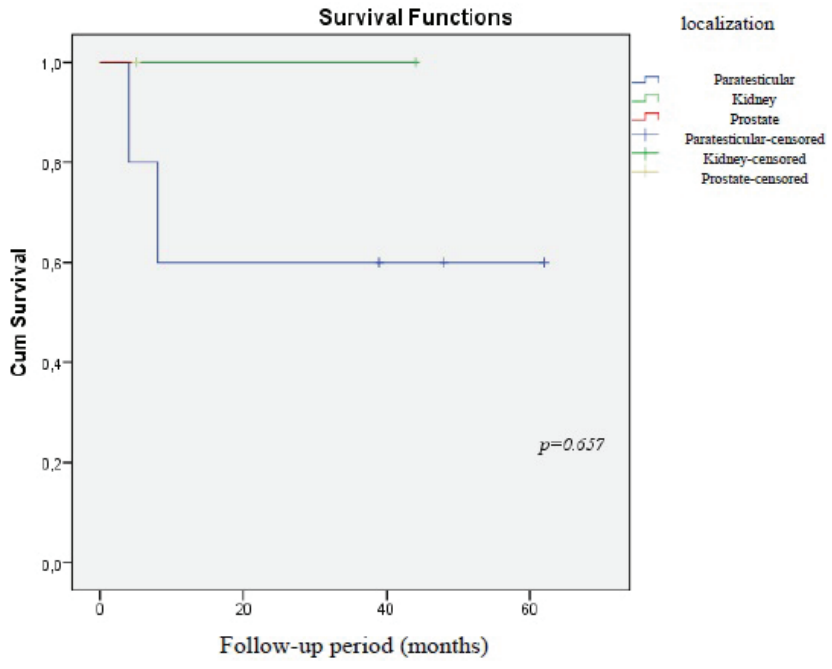

Figure 3. Kaplan-Meier survival curves of all cases according to tumor localization

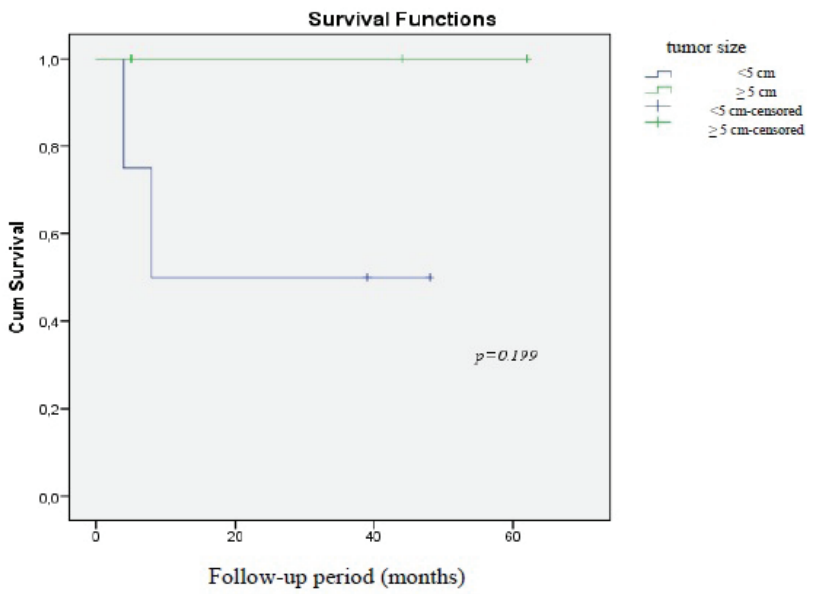

Figure 4. Kaplan-Meier survival curves of all cases according to tumor size

the time of diagnosis. In the patient whose general health status could not tolerate surgery, RT + CT was applied to the prostatic area for palliative purposes. The patient died at $3^{\text {th }}$ month following a rapid PSA progression.

The most common complaint in paratesticular sarcomas is a painless scrotal mass that develops from the mesenchymal elements of the spermatic cord, epididymis and testicular sheath. RMS is the most common soft tissue sarcoma in childhood and is the most common primary paratesticular malignant neoplasm between seven and 36 years of age (mean age 10 years) (15). It accounts for $80 \%$ of paratesticular tumors under the age of 21 and and accounts for $24 \%$ in adults (16). In our study, we observed the histopathological subtype of two paratesticular RMS cases as "embryonal" with a better prognosis and "spindle cell variant", which is considered a subtype of it. The degree of sarcoma in both cases was II according to FNCLCC. In both cases, adjuvant CT was performed following radical orchiectomy. The mean follow-up was 50.5 months (range $=39-62$ months). 
In contrast to paratesticular RMS, there are fewer reported cases of paratesticular LMS and LPS $(17,18)$. Fisher et al. (17) showed that recurrence and metastasis could be prevented in low-grade paratesticular LMS cases by radical orchiectomy. In our case, although radical orchiectomy + inguinal mass excision was performed for complete excision, adjuvant RT was performed because surgical margin positivity was observed. In our case, which was higher grade according to FNCLCC, local recurrence could not be prevented at the $4^{\text {th }}$ month despite multimodal treatment. Paratesticular LPS is mostly well differentiated and it has been reported that the expected survival is longer $(13,18)$. Our patient with grade II paratesticular LPS was followed up without radical adjuvant therapy after radical orchiectomy. No recurrence or progression was observed in the 48-month follow-up.

Since the role of retroperitoneal lymph node dissection (RPLND) in paratesticular sarcomas has not been well defined, controversial views are still available on the additional therapeutic benefit $(13,19,20)$. Therefore, in our patient with grade II, spindle cell variant RMS with $10 \times 8 \mathrm{~mm}$ diameter lymph node in the left paraaortic area at the time of diagnosis, only CT was applied instead of RPLND as adjuvant. No recurrence or progression was observed in this patient at 62 months follow-up.

$\mathrm{MFH}$ is very rare in the urinary system and usually progresses rapidly. Mondainia et al. (2) reported the incidence of MFH in their case series as $4.5 \%$ in all GUS and $11.1 \%$ in paratesticular sarcomas (2). Size, depth and histopathological features of the tumor are important factors for the development of metastasis. Despite multimodal treatment, 3-year survival is approximately $40 \%$ (21). In our study, local recurrence occurred at $8^{\text {th }}$ month in grade III paratesticular MFH despite adjuvant CT after radical orchiectomy. Although we do not know the overall survival status of the patient who is out of follow-up, it is highly likely to show progression in a short time.

SS constitute $1-3 \%$ of all malignant renal masses and $5-10 \%$ of adult soft tissue sarcomas (22). Primary renal SS is much rarer, and approximately 60 cases have been reported in the literature to date (22). Primary renal SS often clinically mimics renal cell carcinoma. Histopathologically, it is difficult to differentiate from Wilms tumor, sarcomatoid kidney cell carcinoma, hemangiopericytoma and undifferentiated carcinoma $(23,24)$. Although the rate of metastasis at the time of diagnosis has been reported to be low in the literature $(23,24)$, the prognosis of renal SS is quite poor, regardless of the type of treatment administered (13). Although the primary treatment approach is surgical, the role of neoadjuvant or adjuvant CT in these cases is not clear (24). The clinical course of our case was consistent with this data and our patient developed metastasis in 2 months following nephrectomy and died at the $5^{\text {th }}$ month despite metastasectomy and adjuvant CT.

Disease-specific survival rate in GUS is worse than in other soft tissue sarcomas (25). This poor prognostic feature of GUS can be explained by presentation at metastatic stage, highgrade tumor, larger tumor size and primary anatomical region of involvement. In addition, heterogeneity between different subgroups of GUS may lead to a significant difference in prognosis among patients (13). According to the multivariate analysis by Dotan et al. (3), increased tumor size, incomplete surgical resection, positive surgical margin and presence of metastasis at the time of diagnosis lead to a significant decrease in disease-specific survival. In addition, tumor size was reported to be predictive of recurrence-free survival, and age, tumor grade and tumor histology as independent predictive factor of metastasis-free survival. Wang et al. (4) detected renal sarcomas, female gender, presence of metastasis at diagnosis and positive surgical margin status as poor prognostic factors affecting recurrence-free survival. They reported the presence of incomplete surgical resection and positive surgical margins as poor prognostic factors affecting metastasis-free survival. In a multicenter study with the largest series (53 patients) in our country, male gender, advanced age ( $\geq 50$ years), metastatic stage at diagnosis, incomplete resection, FNCLCC grade III cases and renal sarcomas were reported as poor prognostic factors (26).

Cho et al. (13) reported 1, 3 and 5-year disease-specific survival rates as $88.9 \%, 76.2 \%$ and $67.7 \%$, respectively, whereas Mondainia et al. (2) reported these rates as $85.9 \%, 62.0 \%$ and $48.8 \%$, respectively. Dotan et al (3). reported 5-year local recurrence rate as $32 \%$, metastasis-free survival rate as $60 \%$, and disease-specific survival rate as $56 \%$. In the largest-scale publication in the literature, Wang et al. (4) found a 5-year local recurrence-free survival rate of $34.6 \%$, metastasis-free survival rate of $34.9 \%$, and overall survival rate of $47.7 \%$. In our median follow-up of 23.5 (range $=4-62$ ) months, we found that the recurrence-free and progression-free survival rates were $50 \%$ and the overall survival rate was $50 \%$. Although our follow-up duration and number of patients were more limited compared to these studies, we observed similar rates.

In our study, local recurrence-free survival was significantly higher in grade II sarcomas compared to grade III according to FNCLCC classification. Cho et al. (13), in their series, reported that tumor grade had a poor prognostic value on disease-specific survival (27). Mondainia et al. (2) reported 5-year survival rates as $100 \%$ for FNCLCC grade $\leq \mathrm{Il}$ and $27.4 \%$ for FNCLCC grade $>$ II. In the same study, disease-free survival rates were $100 \%$ for tumor size $\leq 5 \mathrm{~cm}$ and $11.2 \%$ for tumors $>5 \mathrm{~cm}$. In several publications using the American Joint Committee on Cancer Classification for pathologic tumor grading, 5-year diseasespecific survival rates for low-grade and high-grade tumors were $99 \%$ and $87 \%$, respectively, for tumors $<5 \mathrm{~cm}$. The same rates were $64 \%$ and $48 \%$, respectively, for tumor size $\geq 5 \mathrm{~cm} \mathrm{(3,}$ 28). In our study, during median 23.5 (4-62) months followup, we found the disease-specific rates to be $100 \%$ and $50 \%$ in grade II and III patients, respectively. When we evaluated the effect of tumor size, localization and histopathologic subtype on survival, we could not observe a statistically significant difference. However, we cannot ignore the fact that our shortterm follow-up period and the small number of patients limit our ability to perform a better analysis. In some publications, it has been stated that grade III cases may benefit from adjuvant CT $(29,30)$. Wang et al. (4) reported the absence of adjuvant CT as an independent predictor of poor survival. In our study, four patients in grade III in our study had recurrence and progression despite adjuvant CT and/or RT.

\section{Study Limitations}

The retrospective design of our study, the limited number of patients, therefore the lack of randomization, the short followup period, and the follow-up results belonging to a single center are the main limiting factors. 


\section{Conclusion}

GUSs are a rare group of tumors. Complete surgical resection plays a major role in improving survival in these patients. Survival rates may increase in localized resectable masses with the contribution of adjuvant therapy. The prognosis is poor especially in patients with metastatic disease, prostate sarcomas, MFH and SS. According to our findings, FNCLCC grade is the most important prognostic factor determining recurrence in all adult GUS cases. Therefore, combined multimodal treatments provide a very limited therapeutic effect, especially in grade III sarcomas. Further prospective, randomized, controlled, multicentre, large-population studies with longer follow-up periods are needed to identify prognostic factors that affect survival. To identify specific neoadjuvant or adjuvant therapies according to the tumor subtype are also required.

\section{Ethics}

Ethics Committee Approval: Approval was waived due to retrospective nature of the study.

Informed Consent: Each patient was informed prior to the surgery that their oncological follow-up information such as recurrence, metastasis development, survival analysis may be used without mentioning the patient names and identity information. The information of the patients who did not consent were not used.

Peer-review: Internally peer-reviewed.

\section{Author Contributions}

Surgical and Medical Practice: E.O.G., Concept: E.O.G., Design: I.S., Data Collection or Processing: I.S., Analysis or Interpretation: I.S., E.O.G., Literature Search: I.S., Writting: I.S.

Conflict of Interest: No conflict of interest was declared by the authors.

Financial Support: No financial support was received from any institution or person for our study.

\section{References}

1. Russo P, Brady MS, Colon K, et al. Adult Urological Sarcoma. J Urol 1992; 147:1032-1037.

2. Mondainia N, Pallib D, Saieva C, et al. Clinical Characteristics and Overall Survival in Genitourinary SarcomasTreated with Curative Intent: A Multicenter Study. Eur Urol 2005;47:468-473.

3. Dotan ZA, Tal R, Golijanin D, et al. Adult Genitourinary Sarcoma: The 25-Year Memorial Sloan-Kettering Experience. J Urol 2006;176:2033 2039.

4. Wang $X, T u X$, Tan $P$, et al. Adult genitourinary sarcoma: Clinical characteristics and survival in a series of patients treated at a highvolume institution. Int J Urol 2017;24:425-431.

5. Coindre JM, Terrier P, Bui NB, et al. Prognostic factors in adult patients with locally controlled soft tissue sarcoma. A study of 546 patients from the French Federation of Cancer Centers Sarcoma Group. J Clin Oncol 1996; 14:869-877.

6. Coindre JM, Trojani M, Contesso G, et al. Reproducibility of a histopatological grading system for adult soft tissue sarcoma. Cancer 1986;58:306-309.

7. Lee G, Lee SY, Seo S, et al. Prognostic factors and clinical outcomes of urological soft tissue sarcomas. Korean J Urol 2011;52:669-673.

8. Vuruskan BA, Ozsen M, Coskun B, Yalcinkaya U. Evaluation of incidence and histolopathological findings of soft tissue sarcomas in genitourinary tract: Uludag university experience. Int Braz J Urol 2018;45:68-73.

9. Coleman I, Brennan M F, Alektiar K, Russo P. Adult spermatic cord sarcomas: management and results. Ann Surg Oncol 2003;10:669-675.

10. Jaques DP, Coit DG, Hajdu SI, Brennan MF. Management of primary and recurrent soft tissue sarcoma of the retroperitoneum. Am Surg 1990;212:51-59.

11. Bautista N, Su W, O'Connell TX. Retroperitoneal soft-tissue sarcomas: prognosis and treatment of primary and recurrent disease. Am Surg 2000;66:832-836.

12. Nijhuis PH, Sars PR, Plaat BE, et al. Clinico-pathological data and prognostic factors in completely resected AJCC stage I-III liposarcomas. Ann Surg Oncol 2000;7:535-543.

13. Cho SY, Moon KC, Cheong MS, et al. Localized Resectable Genitourinary Sarcoma in Adult Korean Patients: Experiences at a Single Center. Yonsei Med J 2011;52:761-767.

14. Cheville JC, Dundore PA, Nascimento AG, et al. Leiomyosarcoma of the prostate. Report of 23 cases. Cancer 1995;76:1422-1427.

15. Ferrari A, Bisogno G, Casanova $M$, et al. Paratesticular rhabdomyosarcoma: report from the Italian and German Cooperative Group. J Clin Oncol 2002;20:449-455.

16. Khoubehi B, Mishra V, Ali M, et al. Adult paratesticular tumours. BJU Int 2002;90:707-715.

17. Fisher C, Goldblum JR, Epstein JI, Montgomery E. Leiomyosarcoma of the paratesticular region: a clinicopathologic study. Am J Surg Pathol 2001;25:1143-1149.

18. Montgomery E, Fisher C. Paratesticular liposarcoma: a clinicopathologic study. Am J Surg Pathol 2003;27:40-47.

19. Catton $C N$, Cummings BJ, Fornasier V, et al. Adult paratesticular sarcomas: a review of 21 cases. J Urol 1991;146:342-345.

20. Hermans BP, Foster RS, Bihrle R, et al. Is retroperitoneal lymph node dissection necessary for adult paratesticular rhabdomyosarcoma? J Urol 1998; 160:2074-2077.

21. Celik O, Turk H, Budak S, Ilbey YO. Rare type of bladder cancer: malign fibrous histiocytoma. Arch Ital Urol Androl 2014;86:158-159.

22. Grampurohit VU, Myageri A, Rao RV. Primary renal synovial sarcoma. Urol Ann 2011;3:110-113.

23. Yıkılmaz TN, Baş O, Bezer E, et al. Primary Renal Synovial Sarcoma: A Rare Case Report. J Urol Surg 2016;4:141-143.

24. Gabilondo F, Rodríguez F, Mohar A, et al. Primary synovial sarcoma of the kidney: corroboration with in situ polymerase chain reaction. Ann Diagn Pathol 2008; 12:134-137.

25. Stojadinovic A, Leung DH, Hoos A, et al. Analysis of the prognostic significance of microscopic margins in 2,084 localized primary adult soft tissue sarcomas. Ann Surg 2002;235:424-434.

26. Unal OU, Oztop I, Menekse S, et al. Adult Urological Soft Tissue Sarcomas: A Multicenter Study of the Anatolian Society of Medical Oncology (ASMO). Asian Pac J Cancer Prev 2015;16:4777-4780.

27. Froehner $M$, Lossnitzer $A$, Manseck $A$, et al. Favorable long-term outcome in adult genitourinary low-grade sarcoma. Urology 2000;56:373-377.

28. Lewis JJ, Leung D, Woodruff JM, Brennan MF. Retroperitoneal softtissue sarcoma: analysis of 500 patients treated and followed at a single institution. Ann Surg 1998; 228:355-365.

29. Italiano A, Delva F, Mathoulin-Pelissier S, et al. Effect of adjuvant chemotherapy on survival in FNCLCC grade 3 soft tissue sarcomas: a multivariate analysis of the French Sarcoma Group Database. Ann Oncol 2010;21:2436-2441.

30. No authors listed. Adjuvant chemotherapy for localised resectable softtissue sarcoma of adults: Meta-analysis of individual data. Sarcoma Meta-Analysis Collaboration. Lancet 1997;350:1647-1654. 